\title{
Enhanced S100A4 protein expression is clinicopathologically significant to metastatic potential and p53 dysfunction in colorectal cancer
}

\author{
JOO HEON KIM ${ }^{1}$, CHANG NAM KIM ${ }^{2}$, SOO YOUNG KIM ${ }^{3}$, JUNG SAM LEE ${ }^{1}$, \\ DAEHO CHO ${ }^{4}$, JAE WHA KIM ${ }^{5 *}$ and SUN YOUNG YOON ${ }^{4 *}$
}

\begin{abstract}
Departments of ${ }^{1}$ Pathology, ${ }^{2}$ Surgery and ${ }^{3}$ Preventive Medicine, Eulji University School of Medicine, Daejeon 301-070; ${ }^{4}$ Department of Biological Sciences, Research Center for Women's Disease, Sookmyung Women's University, Seoul 140-742;

${ }^{5}$ Stem Cell Center, Korea Research Institute of Bioscience and Biotechnology (KRIBB), Yusung, Daejeon 305-333, Korea
\end{abstract}

Received October 30, 2008; Accepted December 22, 2008

DOI: 10.3892/or_00000404

\begin{abstract}
To investigate the expression levels of S100A4 in human colorectal carcinoma (CC) and its relationship with clinicopathological parameters and metastatic potential, 73 pathological specimens from patients with CC were examined for S100A4 expression by RT-PCR and immunohistochemistry. An increase of S100A4 mRNA was observed in 19/23 (82.6\%) CC specimens, and S100A4 was up-regulated in $40 / 73(54.7 \%)$ CC cases compared with non-neoplastic mucosal tissues. Upregulation of S100A4 was significantly related to invasion, nodal status, distant metastasis and p53 expression. Next, we investigated whether S100A4 could affect p53 transactivation and stability. Interestingly, it was revealed that treatment with exogenous S100A4 protein reduced transcriptional activity of p53 and abrogated the modification of calcium binding affinity of S100A4 protein. These findings suggested that S100A4 might be involved in the progression and metastasis of human $\mathrm{CC}$, presumably via modulation of the wild-type p53 protein.
\end{abstract}

\section{Introduction}

Human colorectal carcinoma (CC) is one of the major causes of morbidity and mortality worldwide (1). Its tumorigenic mechanism is a multi-step process related to the genetic

Correspondence to: Dr S.Y. Yoon, Research Center for Women's Disease, Sookmyung Women's University, Seoul 140-742, Korea E-mail: pandersy@sookmyung.ac.kr

Dr J.W. Kim, Stem Cell Center, Korea Research Institute of Bioscience and Biotechnology, P.O.Box 115, Daejeon 305-806, Korea

E-mail:wjkim@kribb.re.kr

${ }^{*}$ Contributed equally

Key words: S100A4, p53 transactivation, metastasis, colorectal carcinoma instability associated with genetic alterations (2-4). Currently, there are a few immunohistochemically detectable markers relevant of colorectal carcinoma (5). Of these tumor markers, S100A4 protein has been shown to be associated with progression and worse prognosis of human colorectal cancer (6-8).

S100A4 protein belongs to the S100 subfamily of a calcium binding protein (also called mts 1, p9Ka, CAPL, and calvasculin) $(9,10)$. It is characterized by the EF-hand structural motif and consists of 101 amino acids. It is activated by $\mathrm{Ca}^{2+}$ binding to the two EF-hand motifs, which induces a conformational alteration and homodimerization, resulting in exposure of binding sites for the target protein. Non-muscle tropomyosin (11), non-muscle myosin (12), Liprin beta $1(13)$, and p53 $(14,15)$ are well known target proteins of S100A4. Through interactions with these target proteins, it is believed that $\mathrm{S} 100 \mathrm{~A} 4$ is involved in cytoskeletal dynamics, cell motility and cell growth. Previous studies have shown that S100A4 protein is overexpressed in various human cancers such as malignant gastrointestinal cancer $(6,8,16-18)$, breast cancer $(19,20)$, and non-small cell lung cancer (21), and that this overexpression may influence a patient's clinical prognosis.

To confirm the functional and clinicopathological roles of S100A4 in tumorigenesis of human CC, we analyzed the possible correlation between S100A4 expression and clinocopathological prognostic parameters in 73 human CCs. We also investigated the intracellular biological role of S100A4 in the regulation of p53 transactivation and stability.

\section{Materials and methods}

Patient samples and cell lines. The human CC samples were obtained from patients who underwent routine surgery for colorectal cancer at the Department of Surgery, Eulji University Hospital. For immunohistochemical analysis, the 73 colorectal carcinoma tissues were paired with normal mucosal tissue taken from a site distant from the tumorous lesion. Tissues were then fixed in $10 \%$ neutralized buffered formalin solution for $24 \mathrm{~h}$. Some tissue specimens were immediately frozen after resection and stored in liquid nitrogen 
A
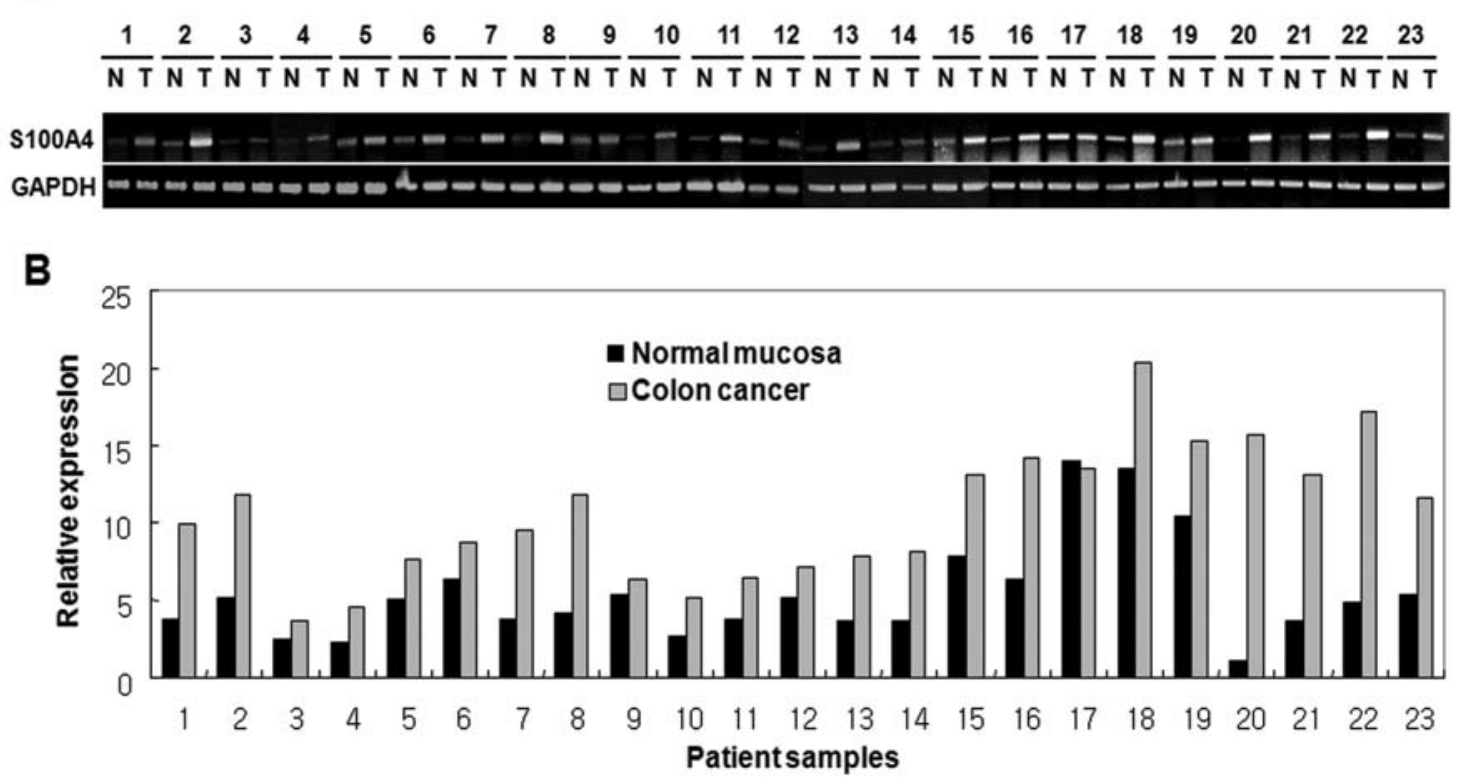

Figure 1. S100A4 gene expression in human CC. (A) Comparative expression levels of S100A4 are shown in 23 normal and colorectal carcinoma samples. (B) Expression levels displayed as the ratio between the signal strength of S100A4 and a reference gene (GAPDH) to compensate for the variation in the amounts of RNA. The expression of S100A4 gene was increased in CC when compared with corresponding normal mucosa.

untill further use. Each patient's clinical status was classified according to the pathological grade of the tumor size, lymph node and metastasis (pTNM) classification system (22). All cell lines used in our studies were purchased from American Type Culture Collection (ATCC, Rockville, MD). The human colon adenocarcinoma cell line, HCT116, and the p53-null human cancer cell line, H1299 were used. These cells were cultured in RPMI-1640 medium supplemented with $10 \%$ fetal bovine serum (Gibco BRL, Grand Island, NY) and $1 \%$ antibiotic-antimycotic solution (Gibco BRL) and kept at $37^{\circ}$ in a humidified incubator maintained with $5 \% \mathrm{CO}_{2}$.

Reverse transcription-polymerase chain reaction ( $R T-P C R)$ analysis. Total RNA was extracted from 23 samples out of 73 colorectal carcinoma and non-tumorous tissues from patients using the AGPC method (23). Extracted RNA was reverse-transcribed using a cDNA synthesis kit (Stratagene, La Jolla, CA) following the instruction manual. cDNA was synthesized using $5 \mu \mathrm{g}$ of total RNA and oligo (dT) primer in $50 \mu 1$ of a solution containing reverse transcriptase. The reverse-transcribed samples were used to amplify the $280 \mathrm{bp}$ fragment of S100A4 by PCR. GAPDH was used as an internal quantitative control. The PCR primer sequences of S100A4 were as follows: 5'-CGGGATCCATGGCGTGCC CTCTGGAG-3' and antisense primer 5'-CCGCTCGAGTCA TTTCTTCCTGGGCTG-3'. GAPDH primer sequences were as follows: sense primer 5'-CCCCTGGCCAAGGTCATC CATGACAACTTT-3' and antisense primer 5'-GGCCAT GAGGTCCACCACCCTGTTGCTGTA-3'. PCR reactions were performed using a Minicycler ${ }^{\mathrm{TM}}$ PCR system (MJ Research, Inc.) using the following cycling parameters: $10 \mathrm{~min}$ at $94^{\circ} \mathrm{C}$ followed by 25 cycles of $1 \mathrm{~min}$ at $94^{\circ} \mathrm{C}, 1 \mathrm{~min}$ at $55^{\circ} \mathrm{C}$, and $1 \mathrm{~min}$ at $72^{\circ} \mathrm{C}$, and a final cycle at $72^{\circ} \mathrm{C}$ for $10 \mathrm{~min}$. Quantitation of PCR products was performed using a Quantity One program (Bio-Rad, Hercules, CA).

Immunohistochemical analysis. Immunohistochemistry was performed to study altered S100A4 expression in 73 human colorectal carcinoma tissues. Mouse monoclonal antibodies against S100A4 (KRIBB) and p53 DO-7 (Dako, Glostrup, Denmark) were used as primary antibodies. In brief, paraffin sections of colorectal carcinoma tissue from patients were deparaffinized with xylene and rehydrated. Antigenic retrieval was performed by submerging slides in citrate buffer $(\mathrm{pH}$ 6.0) and microwaving. The sections were then treated with $3 \%$ hydrogen peroxide in methanol to quench the endogenous peroxidase activity, followed by incubation with $1 \%$ BSA to block the non-specific binding. Primary monoclonal antiS100A4 and p53 antibodies (1:100) were added to the sections and incubated for $60 \mathrm{~min}$ at room temperature. After washing, biotinylated anti-mouse secondary antibody was added to sections, followed by incubation with streptavidinhorseradish-peroxidase complex. The tissue sections were immersed in 3-amino-9-ethyl carbazole (AEC) as a substrate, and counterstained with $10 \%$ Mayer's hematoxylin, dehydrated, and mounted with crystal mount. Non-immune mouse IgG of the same isotype and dilution was used for negative controls. The degree of immunostaining of the formalinfixed, paraffin-embedded sections was evaluated by two independent observers, and moderate to strong cytoplasmic or nuclear staining was considered as a positive reaction. The distribution of S100A4 was scored on a semiquantitative scale as follows: negative/focal ( $<20 \%$ of the cells were positive), moderate (small cell clusters, but $20-70 \%$ of the cells were positive) and diffuse ( $>70 \%$ of the cells were positive). 


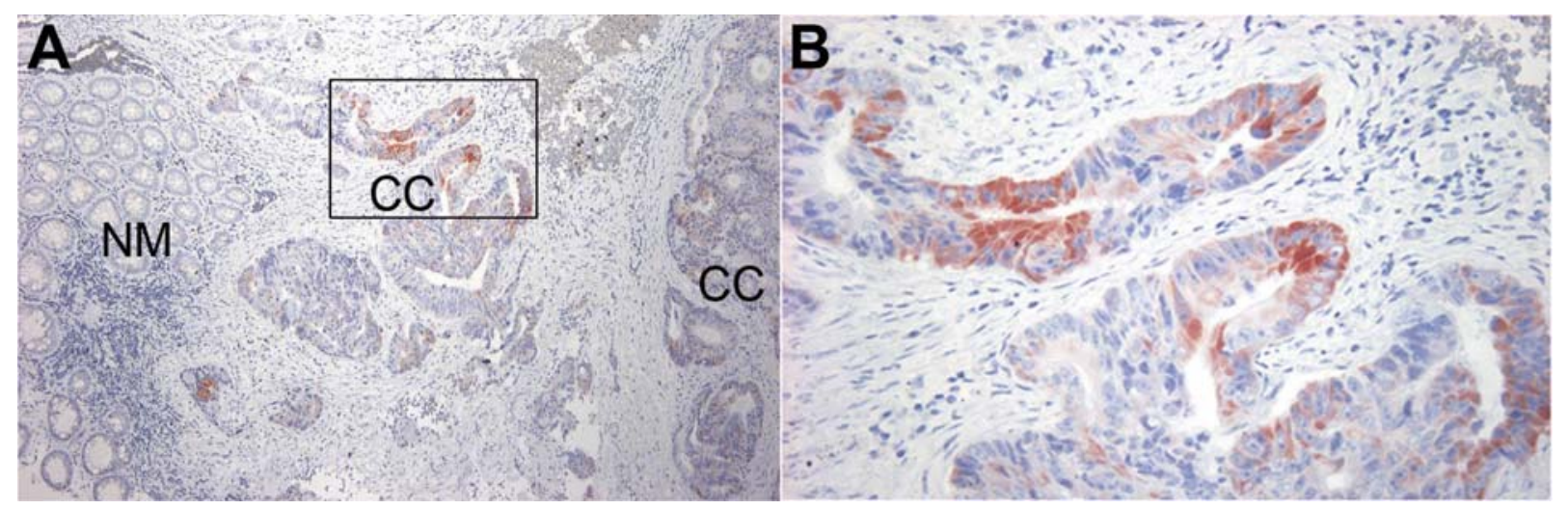

Figure 2. Immunohistochemical staining of S100A4 protein in human CC. (A) S100A4 expression is increased in the CC region compared with that of its adjacent normal mucosal epithelial cells (original magnification, x100). (B) S100A4 protein is distributed throughout the cytosol (magnification, x400). NM, normal mucosa; CC, colorectal carcinoma.
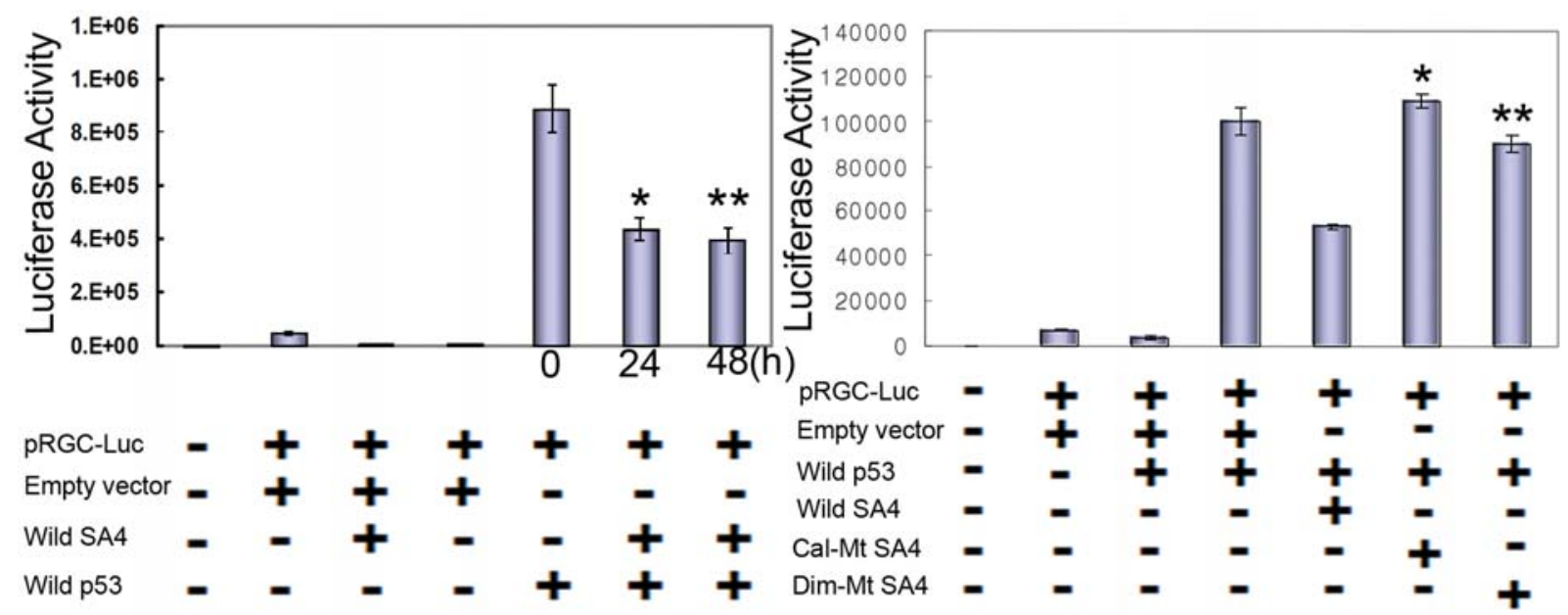

Figure 3. S100A4 inhibits p53 transactivation in human colorectal carcinoma cells, HCT116. (A) Reporter plasmids were co-transfected with various combinations of expression plamids of pcDNA, pcDNA-wild-type p53 and pcDNA-S100A4 in cells. Reporter assay was carried out in triplicate at 24 and $48 \mathrm{~h}$ after transfection. The reporter activity was significantly enhanced by introduction of the wild-type p53. This enhanced activity was reduced by the addition of S100A4 to these cells $\left({ }^{*},{ }^{* *} \mathrm{P}<0.001\right)$. (B) Mutant S100A4 with defective dimerization or calcium binding status did not affect p53 transactivation. Reporter plasmids were co-transfected with various combinations of expression plamids of pcDNA, pcDNA-wild type p53 and pcDNA-mutant S100A4 deficient in dimerization or calcium binding properties. Reporter assay was carried out in triplicate at $24 \mathrm{~h}$ after transfection. $\left({ }^{*},{ }^{* *} \mathrm{P}<0.001\right)$.

Construction of S100A4 mutants deficient in calcium binding and dimerization and luciferase assay. Wild-type p53 expression vector and $\mathrm{pRGC}_{17}$-luciferase reporter gene were a gift from Oren Moshe (Weizmann Institute of Science). Expression plasmids encoding the nucleotide sequence corresponding to the full open reading frame (ORF) for S100A4 were subcloned as 5' BamHI/3' XhoI fragment into pcDNA3.1 (+) (Invitrogen) for transfection. To further evaluate the roles of calcium binding and dimerization in S100A4 in the interaction between the S100A4 and p53 protein, we developed a set of S100A4 mutant constructs deficient in calcium binding and dimerization sites, as reported by Kim et al (24). HCT116 cells were plated at $2 \times 10^{5}$ cells/well on a 6 well plate. After $24 \mathrm{~h}$ the cells were transfected with various combinations of plasmids encoding luciferase under control of the $\mathrm{p} 53$ promoter $(0.5 \mu \mathrm{g})$ and wild-type p53 $(1 \mu \mathrm{g})$ with or without a fragment of S100A4 $(1 \mu \mathrm{g})$ and pcDNA3.1 (+) empty vector using the Fugene 6 reagent (Boehringer Mannheim) as recommended by the manufacturer. A $ß$-galactocidase-expressing vector was included as an internal control for transfection efficiency. For transient transfections, cells were collected after 24 and $48 \mathrm{~h}$. Luciferase assays were performed using a commercial luciferase assay system (Promega, Madison, MI), employing an LB9501 luminometer (Berthold Life sciences, Australia). Results are presented as the average of at least three independent experiments.

Immunoprecipitation and immunoblot analyses. Cell lysis, immunoprecipitation, and washing steps were carried out with the buffer (50 mM Tris, $\mathrm{pH} 7.5,150 \mathrm{mM} \mathrm{NaCl}, 0.5 \%$ Nonidet P-40, $5 \mathrm{mM}$ EDTA, $1 \mathrm{mM}$ PMSF) at $4^{\circ} \mathrm{C}$. Cell extracts were precleared on protein $\mathrm{G}$-agarose suspension (Roche Molecular Biochemicals) and the supernatant was immunoprecipitated using the S100A4 antibody. Immunoprecipitated proteins were collected on protein G-agarose, washed, eluted in gel loading buffer, and separated by SDSPAGE. Proteins were transferred to an Immobilon-P (Milipore) 
Table I. Relationship between S100A4 expression and clinicoparameters in human colorectal carcinoma.

\begin{tabular}{|c|c|c|c|c|}
\hline S100A4 expression & Negative & Lower positive & Higher positive & P-value \\
\hline Age (years) & & & & $\mathrm{NS}^{\mathrm{a}}$ \\
\hline$\leq 50$ & $11(15 \%)$ & $6(8 \%)$ & $2(3 \%)$ & \\
\hline$>50$ & $22(30 \%)$ & $25(34 \%)$ & $7(10 \%)$ & \\
\hline Gender & & & & NS \\
\hline Male & $14(19 \%)$ & $17(23 \%)$ & $2(3 \%)$ & \\
\hline Female & $19(26 \%)$ & $14(19 \%)$ & $7(10 \%)$ & \\
\hline Site & & & & NS \\
\hline Right/transverse colon & $11(15 \%)$ & $7(10 \%)$ & $1(1 \%)$ & \\
\hline Left colon & $7(10 \%)$ & $9(12 \%)$ & $3(4 \%)$ & \\
\hline Rectum & $15(21 \%)$ & $15(21 \%)$ & $5(7 \%)$ & \\
\hline Size & & & & NS \\
\hline$\leq 2$ in diameter & $3(4 \%)$ & $1(1 \%)$ & $0(0 \%)$ & \\
\hline $2-5$ in diameter & $18(25 \%)$ & $14(19 \%)$ & $6(8 \%)$ & \\
\hline$\geq 5$ in diameter & $12(16 \%)$ & $16(22 \%)$ & $3(4 \%)$ & \\
\hline Differentiation & & & & NS \\
\hline Well differentiated & $11(15 \%)$ & $16(22 \%)$ & $6(8 \%)$ & \\
\hline Moderately differentiated & $6(8 \%)$ & $22(30 \%)$ & $3(4 \%)$ & \\
\hline Poorly differentiated & $4(5 \%)$ & $5(7 \%)$ & $0(0 \%)$ & \\
\hline Depth of invasion & & & & 0.004 \\
\hline Muscularis propria & $14(19 \%)$ & $4(5 \%)$ & $1(1 \%)$ & \\
\hline Subserosa & $19(26 \%)$ & $27(37 \%)$ & $8(11 \%)$ & \\
\hline Nodal status & & & & 0.0017 \\
\hline N0 & $23(32 \%)$ & $9(12 \%)$ & $4(5 \%)$ & \\
\hline $\mathrm{N} 1$ & $10(14 \%)$ & $22(30 \%)$ & $5(7 \%)$ & \\
\hline Distant metastasis & & & & 0.0069 \\
\hline M0 & $33(45 \%)$ & $25(34 \%)$ & $7(10 \%)$ & \\
\hline M1 & $0(0 \%)$ & $6(8 \%)$ & $2(3 \%)$ & \\
\hline CEA & & & & NS \\
\hline$<7$ & $26(36 \%)$ & $20(27 \%)$ & $4(5 \%)$ & \\
\hline$\geq 7$ & $7(10 \%)$ & $11(15 \%)$ & $5(7 \%)$ & \\
\hline p53 & & & & 0.0701 \\
\hline Negative & $14(19 \%)$ & $9(12 \%)$ & $0(0 \%)$ & \\
\hline Positive & $19(26 \%)$ & $22(30 \%)$ & $9(12 \%)$ & \\
\hline
\end{tabular}

${ }^{a} \mathrm{NS}$, non-significant.

membrane and then probed with the primary antibody p53 Ab-6 (Oncogene Science, La Jolla, CA). The blot was analyzed by standard Western blotting procedure with an enhanced chemiluminescence detection system (ECL kit; Amersham, Arlington Heights, IL).

Statistical analysis. The relationship between the results of the immunohistochemical study and the clinicopathological parameters was determined using the SAS ${ }^{\circledR}$ software package (version 8.01; SAS Institute, Cary, NC). Univariate and multivariate analyses were carried out using the Proc logistic module. Probability values $(\mathrm{P}<0.05)$ were considered to be statistically significant.

\section{Results}

S100A4 expression in human colorectal carcinoma. Expression patterns of S100A4 in human colorectal carcinomas were examined through RT-PCR and immunohistochemical analysis. The relative levels of expression of S100A4 in 23 colorectal carcinoma tissues were compared with those of non-tumorous tissues by RT-PCR. The 
Table II. Multivariate logistic regression analysis with S100A4 expression.

\begin{tabular}{lccc}
\hline Categories & P-value & Odds ratio & $\begin{array}{c}95 \% \text { confidence } \\
\text { limits }\end{array}$ \\
\hline $\begin{array}{l}\text { Nodal } \\
\text { status }\end{array}$ & $<0.0001$ & 4.283 & $1.951-9.402$ \\
p53 & 0.0015 & 3.102 & $1.350-7.129$ \\
$\begin{array}{l}\text { Distant } \\
\text { metastasis }\end{array}$ & 0.0163 & 2.453 & $1.512-5.712$ \\
\hline
\end{tabular}

expression levels were expressed as a ratio between S100A4 and the reference gene (GAPDH) to correct for variation in the amounts of mRNA. The S100A4 mRNA level was significantly increased $(\mathrm{P}<0.0001)$ in all of the examined human colorectal carcinomas when compared to its corresponding normal mucosal tissue (Fig. 1). Increased expression of S100A4 mRNA in tumor tissue was defined as at least 2-3 times higher than that seen in normal colonic mucosal tissue. Immunohistochemical examination of the tumor tissues using monoclonal antibody specific to S100A4 showed that 40 of $73(55 \%)$ colorectal tumor tissues samples had increased levels of S100A4. Normal colorectal mucosa from patients shows negative or weak S100A4 staining in the mucosal epithelial cells. We found that levels of S100A4 were significantly higher in colorectal carcinomas compared to normal mucosal tissue from cancer patients (Fig. 2), and that S100A4 was mostly localized in the cytoplasm but was also seen in nuclear areas of tumor cells. The expression levels of S100A4 in colorectal carcinoma samples revealed negative/focal, moderately and diffuse positive immunoreactivity in 33, 31 and 9 cases, respectively (data not shown).

Relationship between S100A4 expression and clinicopathological parameters in human colorectal carcinoma. We investigated the expression level of S100A4 and various clinicopathological parameters in colorectal carcinomas to determine whether there is a relationship between the two. There was significant correlation between expression of S100A4 and clinicopathological parameters, such as depth of invasion $(\mathrm{P}=0.004)$, distant metastasis $(\mathrm{P}=0.0069)$, nodal status $(\mathrm{P}=0.0017)$ and $\mathrm{p} 53$ overexpression $(\mathrm{P}=0.07)$ in univariate analysis (Table I). Also, multivariate analysis using data from all parameters confirmed that S100A4 expression, depth of invasion, metastasis and p53 overexpression were significant co-variates $(\mathrm{P}<0.01)$ (Table II).

S100A4 down-regulates p53 transcriptional activities and stability. To assess the biological role of S100A4, we investigated whether S100A4 affects the transcriptional activity of tumor suppressor p53 using a reporter assay. The intracellular role of S100A4 in transcriptional activity of the wild-type p53 was investigated by co-transfection of various combinations of expression vectors with S100A4 containing a full ORF length and reporter gene with a luciferase tagged p53 promoter in H1299 cell line, which is an S100A4- and

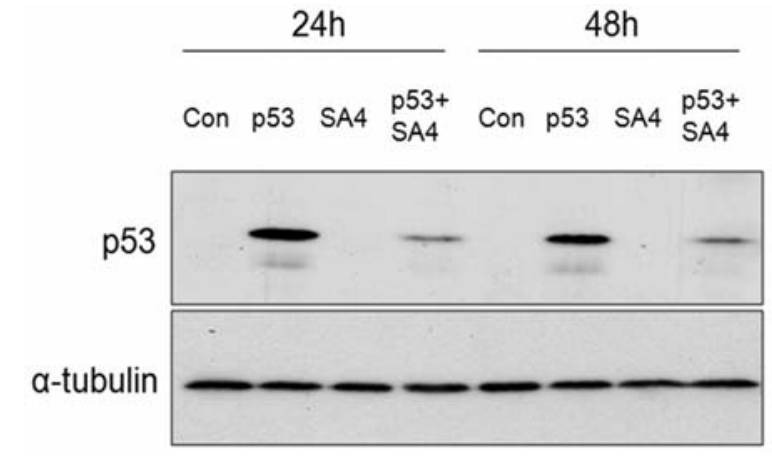

Figure 4. The induction of exogenous S100A4 destabilizes wild-type p53 in H1299 (p53-null) cells. Cells were co-transfected with p53 (wild-type) and a full fragment of S100A4 and then further incubated for 24 or $48 \mathrm{~h}$ before harvesting. p53 was immunoprecipitated with an anti-p53 antibody and analyzed by SDS-PAGE and Western blot analyses using p53 antibody. $\alpha$-tubulin was used as a loading control.

p53-negative cell line (Fig. 3). The value of significantly inhibited transactivity with co-transfection of S100A4 was tested using a luciferase activity assay and analyzed by t-test. Co-transfection assay revealed that transcriptional activity of the wild-type p53 in the presence of S100A4 was suppressed in H1299 cells $(\mathrm{P}<0.0001$, Fig. 3A). Luciferase reporter gene assay showed that S100A4 mutants that are defective in either their ability to dimerize or in calcium binding were unable to interact with wild-type p53 (Fig. 3B).

To confirm these results, we performed co-transfection of the S100A4 and p53 protein expression vectors in H1299 cells, Western blot analysis and MTS assay (Fig. 4). Western blot analysis showed that the protein levels of p53 decreased following co-transfection with S100A4 protein.

\section{Discussion}

The S100 proteins belong to a superfamily of proteins containing an EF-hand $\mathrm{Ca}^{2+}$-binding mortif. Of these, several S100 proteins such as S100A1, S100A4, S100A5, and S100A6 are found in human colon tissues. Involvement of S100A4 and S100A6 has been proposed to play important biologic roles in tumor progression and metastasis of human colorectal cancer (7). Human colorectal adenocarcinoma is one of the most common malignancies in the world and the prognosis of patients with this disease has not changed over the last several decades (1-3). Therefore, it is important to identify any potential tumor marker that is associated with pathophysiologic processes of colorectal carcinoma.

S100A4 gene has been isolated as a gene specifically expressed in murine and human metastatic tumor cells (9). Expression of S100A4 in human colorectal cancer has been correlated with poor prognosis, however, little is known about the intracellular role of S100A4 in the pathophysiologic process of tumorigenesis and metastasis of human colorectal carcinoma. Of the known target proteins that interact with S100A4, p53 is a tumor suppressor protein and a transcriptional factor involved in cell cycle regulation and apoptosis. Grigorian et al have demonstrated that S100A4 binds to the C-terminal regulatory domain of tumor suppressor p53 
protein and enhances p53 dependent apoptosis in human osteosarcoma cell lines (15). Herein, we confirmed a physical interaction between S100A4 and p53 in the human colon adeno-carcinoma cell lines HCT116 and KM12 with wildtype 53 and mutant-type p53, respectively. As previously described by Chen et al, a physical binding between S100A4 and p53 in tumor cells is likely to occur in part independently of its mutational status (14). Furthermore, we demonstrate that S100A4 alters p53 function via protein-protein interaction and negatively modulates the transcriptional function of the wild-type p53. We also found that the calcium binding and dimerization status of S100A4 is critical in the interaction between S100A4 and p53 protein. Taken together, these findings suggest that $\mathrm{S} 100 \mathrm{~A} 4$ regulates p53-dependent survival of tumor cells in the colorectal adenocarcinoma.

In the present study, we examined the level of S100A4 gene products using RT-PCR in 23 matched colon cancer and adjacent normal colon samples. The results showed that nearly all colorectal carcinoma samples overexpressed S100A4 at the mRNA level. Immunohistochemical staining showed that $55 \%$ of colorectal carcinoma samples overexpressed S100A4 protein, which was largely detected in the tumor cells. Additionally, increased expression levels of S100A4 correlated significantly with tumor invasion and metastases in univariate and multivariate analyses. Interestingly, S100A4 overexpression correlated with p53 positive immunohistostaining in human colorectal cancer. The positive immunohistostaining indicates that p53 is mutated in these cases, since the level of wild-type p53 is at or below the level of detection in paraffin-embedded tissue samples. In the present study, the presence of S100A4 strongly down-regulates the wild-type p53 protein in cotransfection luciferase assay. Univariate and multivariate analyses revealed that inceased S100A4 expession significantly correlates with p53 overexpression. Some studies have demonstrated that mutant $\mathrm{p} 53$ regulates the expression and promoter activity of endogenous genes, such as c-myc (25), EGFR (26,27), PCNA (28), MDR-1 (29), causing an increase in oncogenic activities. Taken together, we propose that elevated S100A4 protein expression may promote positive selection of the more malignant phenotype in the early process of tumorigenesis via modulating the wild-type p53-regulated proteins, resulting in aggressive and metastatic clonal expansion regulated by mutant p53 in the more advanced progression of human colorectal carcinoma. However, further investigations are needed to reveal the pathological importance of S100A4 in human colorectal carcinoma.

In conclusion, the present study suggests that alteration of S100A4 can function, at least in part, as a regulator of p53 protein in the development and progression of colorectal carcinoma. Also, S100A4 may be a powerful prognostic marker for human colorectal carcinoma.

\section{Acknowledgements}

This work was supported by the grant (KGM1210821) from the 21C Frontier Stem Cell Research Project, the Korea Science and Engineering Foundation (KOSEF) through the Research Center for Women's Diseases (RCWD) at
Sookmyung Women's University and 2007 Eulji Research Grant (EJRG-07-002-12E05).

\section{References}

1. Landis SH, Murray T, Bolden S and Wingo PA: Cancer statistics, 1998. CA Cancer J Clin 48: 6-29, 1998.

2. Gayet J, Zhou XP, Duval A, et al: Extensive characterization of genetic alterations in a series of human colorectal cancer cell lines. Oncogene 20: 5025-5032, 2001.

3. Kinzler $\mathrm{KW}$ and Vogelstein B: Lessons from hereditary colorectal cancer. Cell 87: 159-170, 1996.

4. Shih IM, Zhou W, Goodman SN, Lengauer C, Kinzler KW and Vogelstein B: Evidence that genetic instability occurs at an early stage of colorectal tumorigenesis. Cancer Res 61: 818-822, 2001.

5. McLeod HL and Murray GI: Tumour markers of prognosis in colorectal cancer. Br J Cancer 79: 191-203, 1999.

6. Gongoll S, Peters G, Mengel M, et al: Prognostic significance of calcium-binding protein S100A4 in colorectal cancer. Gastroenterology 123: 1478-1484, 2002.

7. Bronckart Y, Decaestecker C, Nagy N, et al: Development and progression of malignancy in human colon tissues are correlated with expression of specific $\mathrm{Ca}(2+)$-binding $\mathrm{S} 100$ proteins. Histol Histopathol 16: 707-712, 2001.

8. Takenaga K, Nakanishi $\mathrm{H}$, Wada $\mathrm{K}$, et al: Increased expression of S100A4, a metastasis-associated gene, in human colorectal adenocarcinomas. Clin Cancer Res 3: 2309-2316, 1997.

9. Schafer BW and Heizmann CW: The S100 family of EF-hand calcium-binding proteins: functions and pathology. Trends Biochem Sci 21: 134-140, 1996.

10. Barraclough R: Calcium-binding protein S100A4 in health and disease. Biochim Biophys Acta 1448: 190-199, 1998.

11. Takenaga K, Nakamura Y, Sakiyama S, Hasegawa Y, Sato K and Endo H: Binding of pEL98 protein, an S100-related calcium-binding protein, to nonmuscle tropomyosin. J Cell Biol 124: 757-768, 1994.

12. Kriajevska M, Tarabykina S, Bronstein I, et al: Metastasisassociated Mts1 (S100A4) protein modulates protein kinase C phosphorylation of the heavy chain of nonmuscle myosin. J Biol Chem 273: 9852-9856, 1998.

13. Kriajevska M, Fischer-Larsen M, Moertz E, et al: Liprin beta 1, a member of the family of LAR transmembrane tyrosine phosphatase-interacting proteins, is a new target for the metastasis-associated protein S100A4 (Mts1). J Biol Chem 277: 5229-5235, 2002.

14. Chen H, Fernig DG, Rudland PS, Sparks A, Wilkinson MC and Barraclough R: Binding to intracellular targets of the metastasis-inducing protein, S100A4 (p9Ka). Biochem Biophys Res Commun 286: 1212-1217, 2001.

15. Grigorian M, Andresen S, Tulchinsky E, et al: Tumor suppressor p53 protein is a new target for the metastasisassociated Mts1/S100A4 protein: functional consequences of their interaction. J Biol Chem 276: 22699-22708, 2001.

16. Ninomiya I, Ohta T, Fushida S, et al: Increased expression of S100A4 and its prognostic significance in esophageal squamous cell carcinoma. Int J Oncol 18: 715-720, 2001.

17. Yonemura Y, Endou Y, Kimura K, et al: Inverse expression of S100A4 and E-cadherin is associated with metastatic potential in gastric cancer. Clin Cancer Res 6: 4234-4242, 2000.

18. Taylor S, Herrington S, Prime W, Rudland PS and Barraclough R: S100A4 (p9Ka) protein in colon carcinoma and liver metastases: association with carcinoma cells and T-lymphocytes. $\mathrm{Br}$ J Cancer 86: 409-416, 2002.

19. Platt-Higgins AM, Renshaw CA, West CR, et al: Comparison of the metastasis-inducing protein S100A4 (p9ka) with other prognostic markers in human breast cancer. Int J Cancer 89: 198-208, 2000.

20. Rudland PS, Platt-Higgins A, Renshaw C, et al: Prognostic significance of the metastasis-inducing protein S100A4 (p9Ka) in human breast cancer. Cancer Res 60: 1595-1603, 2000.

21. Kimura K, Endo Y, Yonemura Y, et al: Clinical significance of S100A4 and E-cadherin-related adhesion molecules in nonsmall cell lung cancer. Int J Oncol 16: 1125-1131, 2000.

22. Wittekind C, Compton CC, Greene FL and Sobin LH: TNM residual tumor classification revisited. Cancer 94: 2511-2516, 2002.

23. Chomczynski $\mathrm{P}$ and Sacchi N: Single-step method of RNA isolation by acid guanidinium thiocyanate-phenol-chloroform extraction. Anal Biochem 162: 156-159, 1987. 
24. Kim EJ and Helfman DM: Characterization of the metastasisassociated protein, S100A4. Roles of calcium binding and dimerization in cellular localization and interaction with myosin. J Biol Chem 278: 30063-30073, 2003.

25. Chen TM and Defendi V: Functional interaction of p53 with HPV18 E6, c-myc and H-ras in 3T3 cells. Oncogene 7: 1541-1547, 1992.

26. Ludes-Meyers JH, Subler MA, Shivakumar CV, et al: Transcriptional activation of the human epidermal growth factor receptor promoter by human p53. Mol Cell Biol 16: 6009-6019, 1996.
27. Horak E, Smith K, Bromley L, et al: Mutant p53, EGF receptor and c-erbB-2 expression in human breast cancer. Oncogene 6: 2277-2284, 1991.

28. Xu J and Morris GF: p53-mediated regulation of proliferating cell nuclear antigen expression in cells exposed to ionizing radiation. Mol Cell Biol 19: 12-20, 1999.

29. Zhan M, Yu D, Lang A, Li L and Pollock RE: Wild type p53 sensitizes soft tissue sarcoma cells to doxorubicin by downregulating multidrug resistance- 1 expression. Cancer 92: 1556-1566, 2001 